\title{
Kietụjų dalelių taršos galandinimo proceso metu tyrimas
}

\author{
Jonas Matijošius ${ }^{1 *}$, Alfredas Rimkus ${ }^{1}$, Mantas Juchnevičius ${ }^{1}$, Virginijus Daugèla ${ }^{1}$, \\ Saulius Stravinskas ${ }^{1}$, Audrius Čereška ${ }^{1,2}$ \\ ${ }^{1}$ Vilniaus technologiju ir dizaino kolegija, Technikos fakultetas \\ Olandu g. 16,01100Vilnius, LT.el.paštas j.matijosius@vtdko.lt \\ ${ }^{2}$ Vilniaus Gedimino technikos universitetas, Mechanikos fakultetas \\ Basanavičiaus g. 28,03224 Vilnius, LT. el.paštas audrius.cereska@vilniustech.lt
}

(Gauta 2021 m. sausio mèn.; atiduota spaudai 2021 m. vasario mèn.; prieiga internete nuo $2021 \mathrm{~m}$. gegužès 11 d.)

\begin{abstract}
Anotacija
Nuolat modernejjant pramonei vis labiau ị akirati patenka metalo apdirbimo darbinèje aplinkoje esantys organizmai ir jų galimai sukeliami apdirbimo procesų metu išsiskiriančių kietujų dalelių, patekusių i gyvų orga-nizmų vidų, neigiami padariniai. Smulkiausios kietosios dalelès, patekusios ị žmogaus organizmą, patenka ne tik ị plaučių bronchinio medžio smulkiausius taškus, tačiau gali užteršti ir kraujotaką, todèl tyrimo metu buvo nusp-ręsta identifikuoti kietujų dalelių taršos pokytị galandinimo proceso metu, įvertinti darbinès aplinkos trūkumus ir pateikti efektyvius problemos sprendimo būdus.
\end{abstract}

Reikšminiai žodžiai: galandinimas, kietosios dalelès, darbo higiena, tarša.

\section{Abstract}

As the industry continues to modernize, there is an increasing focus on organisms in the work environment which are the potentially adverse effects of the release of particulate matter from working processes into living organisms. Bearing in mind that the finest particulate matter enters the human body not only at the smallest points of the bronchial lung, but may also contaminate the bloodstream, the study decided to identify changes in particulate matter contamination during the sharpening process.

Key words: Sharpening, particulate matter, occupational hygiene, pollution

\section{Ivadas}

Šiuolaikinis gamybos procesas reikalauja vis didesnị dèmesi skirti aplinkosauginiams klausimams (Merklein et al., 2021). Priimta, kad tvari gamyba asocijuojasi ne tik su nauju technologijų gamyboje taikymu, bet ir tvarių sprendimų, leidžiančių užtikrinti aukštus kokybės ir aplinkosaugos standartus, paieška (Molaei et al., 2021). Žinoma, kad pramonès revoliucija, o tiksliau, dabartinis jos trečios kartos formatas, verčia pačią gamybą automatizuotu ir robotizuotu produktu, kuri galima sąlyginai pigiai pritaikyti bet kurioje pasaulio vietoje (Senthil et al., 2020). Toks gamybos transformavimas iš dabar vyraujančios ị labiau modernizuotą reikalauja didelių lěšų, technologinio ir žmogiškojo potencialo (Johnson et al., 2020). Nenumaldant gaunamos naudos kai kurių gamybos procesų modernizavimas yra sunkiai įsivaizduojamas dẻl šių priežasčių:

- Pernelyg paprastas gamybos operacijos pobūdis palyginti su visu gamybos operacijų kompleksu (Bandyopadhyay et al., 2020);

- Finansiškai labai brangus tos operacijos modernizavimas (Chen et al., 2020); 2021).

- Technologinis gamybos potencialas yra silpnai pritaikytas tos operacijos pobūdžiui (Liu,

Todèl yra akcentuojamas dalinis arba kombinuotas gamybos pobūdžio pokytis, leidžiantis kai kurias gamybos proceso operacijas palikti nepakitusias (Singh et al., 2020).

Savo ruožtu toks gamybos proceso modifikavimas turi užtikrinti proceso tvarumo reikalavimus, o ypač tuos, kurie yra susiję su aplinkosauga (Petunin et al., 2019). Žinoma, kalbant apie aplinkosaugą nereikia pamiršti ir darbo higienos klausimų, nes kokybiškam ir efektyviam darbui, kuris yra pagrindinis gamybos proceso akstinas, būtinas ir darbo vietos ergonominis 
veiksnys (Maldonado-Macías et al., 2015). Todẻl darbo vietos ergonomiką metalo apdirbimo imonèje nusako atitinkami norminiai aktai:

- HN 42:2009 „Gyvenamujų ir visuomeninių pastatų patalpų mikroklimatas“ (V-1081 Dėl Lietuvos higienos normos HN 42:2009 „Gyvenamujų ir visuomeninių pastatų patalpu mikroklimatas...," 2009);

- HN 98:2014 „Natūralus ir dirbtinis darbo vietų apšvietimas. apšvietos mažiausios ribinès vertès ir bendrieji matavimo reikalavimai“ (V-520 Dèl Lietuvos Respublikos sveikatos apsaugos ministro 2000 m. gegužès 24 d. įsakymo Nr. 277 „Dèl L...,” 2014);

- XIII-2711 Lietuvos Respublikos įstatymas dèl Tarptautinės darbo organizacijos $1930 \mathrm{~m}$. konvencijos dèl prevencijos (XIII-2711 Lietuvos Respublikos įstatymas dèl Tarptautinès darbo organizacijos $1930 \mathrm{~m}$. konvencijos dèl prive..., 2019);

- Dèl Elektrinių ir elektros tinklų eksploatavimo taisyklių patvirtinimo“ (1-211 Dèl Elektrinių ir elektros tinklų eksploatavimo taisyklių patvirtinimo, 2012);

- „Dèl Galios elektros įrenginių įrengimo taisyklių patvirtinimo“ (1-1 Dèl Galios elektros įrenginių ịrengimo taisyklių patvirtinimo, 2012);

Remiantis jais aplinkosauginiu aspektu svarbiausias yra pirmasis, kuris apibendrina ir taršą kietosiomis dalelëmis darbo vietoje.

Galandinimo operacija gamybos proceso metu nors ir yra parengiamoji, bet labai svarbi siekiant užtikrinti tolimesni gamybos proceso efektyvumą, ypač kai kalbama apie metalo apdirbimo įmones (Rostek and Homberg, 2017). Taršos kietosiomis dalelėmis identifikavimas leidžia numatyti saugos priemones, būtinas užtikti tiek higienos reikalavimus, tiek darbo vietos ergonominius principus, juk atsirandantis darbuotojo nuovargis ir kiti sveikatos sutrikimai turi įtakos pačiam gamybos proceso efektyvumui.

Pagrindinis darbo objektas yra galandinimo staklių skleidžiama tarša kietosiomis dalelėmis.

Tyrimo tikslas - identifikuoti galandinimo staklių taršos kietosiomis dalelèmis mastą.

Tikslui išspręsti formuojami šie uždaviniai:

1. Taršos kietosiomis dalelemis identifikavimas naudojant skirtingus prietaisus ir ju rezultatų koreliavimas.

2. Taršos kietosiomis dalelėmis identifikavimas pagal kietụjų dalelių dispersiškumą.

\section{Tyrimo metodika}

Prieš darant eksperimentinius tyrimus atliekamas matavimo prietaisų kalibravimas, siekiant patikrinti, ar prietaisai, kuriais bus atliekami eksperimentiniai matavimai, yra neužteršti ir tinkami eksperimentams atlikti. Tiriamoji medžiaga - $40 \mathrm{~mm}$ ilgio plieno strypeliai, kurie 60 sekundžių kontaktuodami su galandinimo staklèse besisukančiu galandinimo disku buvo nugalandinami po 5 mm. Kiekvieno bandymo ciklo metu buvo naudojami vis kiti, tačiau tos pačios sandaros plieno strypeliai.

Siekiant ịvertinti darbinès aplinkos užterštumą bandymai buvo skirstomi i tris etapus. Pirmuoju etapu kietujų dalelių analizatoriais buvo tiriamas bendras kietujų dalelių kiekis esantis erdvejje, prieš pradedant tyrimą bandymas buvo atliekamas 6 kartus. Antruoju etapu kietujų dalelių analizatoriais buvo tiriamas kietujų dalelių kiekis aplinkoje dirbant galandinimo staklèmis, kai buvo ijungtas galandinimo staklių abrazyvo ištraukimo mechanizmas su kietujjų dalelių nusodinimui skirtu oro filtru. Bandymas kartotas 6 kartus. Trečiuoju etapu kietujų dalelių analizatoriais buvo tiriamas susidariusių kietujų dalelių kiekis išvėdinus tiriamąją aplinką, bandymas taip pat buvo kartotas 6 kartus.

Tyrimai buvo atliekami trimis etapais:

- $\quad$ prieš galandinimą; 
- $\quad$ galandinimo metu;

- 1 val. po galandinimo.

Valanda po galandinimo buvo pasirinkta remiantis tuo, kad dažniausiai metalo apdirbimo imonèse pasitaikanti pietų pertraukos trukmè yra 1 valanda. Jos metu staklynas nedirba ir galima optimali patalpų ventiliacija.

Tyrimo metu veikiant galandinimo staklëms kietujų dalelių analizatoriai nuo staklių buvo nutolę 1 metro atstumu, kad galètume užfiksuoti, kiek įmanoma artimesnị ryši su žmogumi, dirbančiu prie galandinimo staklių ir ịkvepiančiu aplinkoje susidariusių kietujjų dalelių, išsiskiriančių apdirbimo metu kiekį, patenkantị į žmogaus plaučius.

Bandymo metu naudoti kietųjų dalelių koncentracijos analizatoriai:

„APC ErgoTouch 2“ (daleliu skersmuo (6 kanalai) - 0,2 $\mu \mathrm{m}, 0,5 \mu \mathrm{m}, 1 \mu \mathrm{m}, 3 \mu \mathrm{m}, 5 \mu \mathrm{m}, 10$ $\mu \mathrm{m}$; matavimo laikas - sekundès; tūris $-0,01 \pm 5 \%$ 1/min. tikslumu).

TSI P-Trak dalelių matavimo diapazonas 2,5-10 $\mu \mathrm{m}$, matavimo laikas - sekundès; tūris $0,01 \pm 1 \% 1 / \mathrm{min}$. tikslumu.

Atliktų bandymų duomenys iš oro dalelių kiekybinių pasiskirstymo analizatorių „Ergotoutch Pro 2" ir TSI P-Trak perkeliami apdoroti ị kompiuterio operacinę sistemą. Akcentuojama, kad abu prietaisai yra specializuoti, t. y. pritaikyti matuoti patalpų taršą kietosiomis dalelėmis. Skiriasi jų tikslumas.

\section{Tyrimo rezultatai}

Tyrimo rezultatų vertinimą galima suskirstyti ị dvi dalis:

- bendrasis kietujų dalelių tyrimas, kurio metu apibendrinama suminé kietujų dalelių koncentracija (dalelių dydis matuojamas 2,5-10 mikronų diapazonu);

- kietujų dalelių tyrimas pagal jų dispersiškumą imamiems diapazonams $0,2 \mu \mathrm{m}, 0,5 \mu \mathrm{m}, 1$ $\mu \mathrm{m}, 3 \mu \mathrm{m}, 5 \mu \mathrm{m}, 10 \mu \mathrm{m}$.

Tyrimo rezultatai atskleidè, kad kietujų dalelių lygis prieš pradedant eksperimentą buvo pastovus ir jo pokyčio priklausomai nuo atliktų matavimo skaičiaus nebuvo (1 pav.).

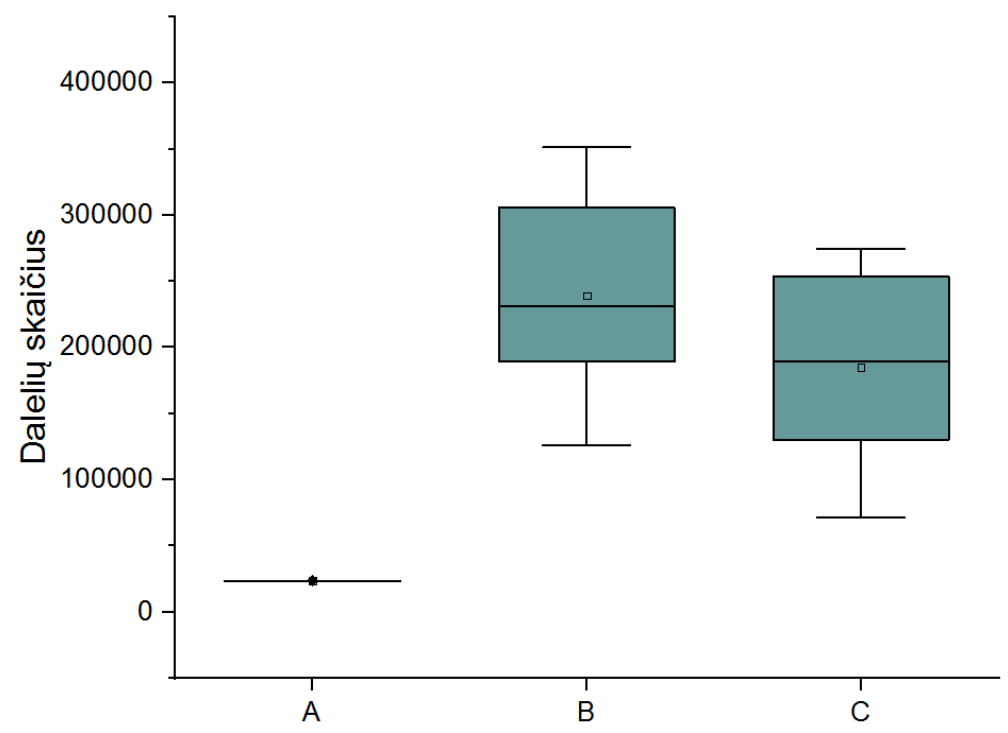

1 pav. Taršos kietosiomis dalelėmis reikšmė (intervale 2,5-10 $\mu \mathrm{m}$ ), kur A - tarša prieš galandinimo procesą; B - tarša galandinimo proceso metu; $\mathrm{C}$ - tarša išvėdinus tiriamąą aplinką 1 valandą po galandinimo proceso

Fig. 1 Particulate pollution value (in the range of 2.5-10 $\mu \mathrm{m}$ ), where A - pollution before the sharpening process; $B$ pollution during the sharpening process; $C$ - pollution after derivation of the test environment 1 hour after the sharpening process

32 
Galandinimo proceso metu dalelių išsibarstymas vyravo apie 236000 ribą ir priklausomai nuo eksperimentų skaičiaus kito $40 \%$ lauko ribose (305000-223000 dalelių). Tyrimo metu pastebètos ir dalelių skaičiaus reikšmès, išeinančios iš statistinio patikimumo ribų. Jos minimali reikšmè buvo 126000, o maksimali 351000 dalelių. Išvėdinus patalpą matomas žymus dalelių pokytis. Kietųu dalelių sumažèjo visame matavimo intervale, dalelių išsibarstymas vyravo apie 187000 ribą ir priklausomai nuo eksperimentų skaičiaus kito 35 \% lauko ribose (253000-133000 dalelių).

Tyrimo metu pastebėtos ir dalelių skaičiaus reikšmès išeinančios iš statistinio patikimumo ribų. Jos minimali reikšmė buvo 71000, o maksimali 274000 dalelių. Analizuojant rezultatus galima teigti, kad vienos valandos vėdinimo periodas yra nepakankamas, ir pagal stebimas tendencijas ji būtina ilginti tris kartus. Tačiau toks ilginimas nèra ekonomiškai pagrịstas, bet pritaikius specializuotas galandinimo patalpas ir pati procesą modeliuojant laike galima pasiekti kietujų dalelių taršos rodiklius, buvusius prieš galandinimo proceso pradžią.

Analizuojant pačių mažiausių dalelių $(0,2 \mu \mathrm{m})$ pasiskirstymą pastebèta $(2$ pav.), kad jų kiekis nors ir yra mažesnis patalpai išvėdinant vieną valandą, bet pakankamai didelis. Tai gali lemti darbo sąlygų pablogèjimą, kuris turès ịtakos darbo efektyvumui. Todèl esant tokiai dalelių taršai būtina užtikrinti papildomą patalpų ventiliaciją. Dalelių išsibarstymo ribos yra labai panašios ir valandos laikotarpiu mažèja tolygiai.

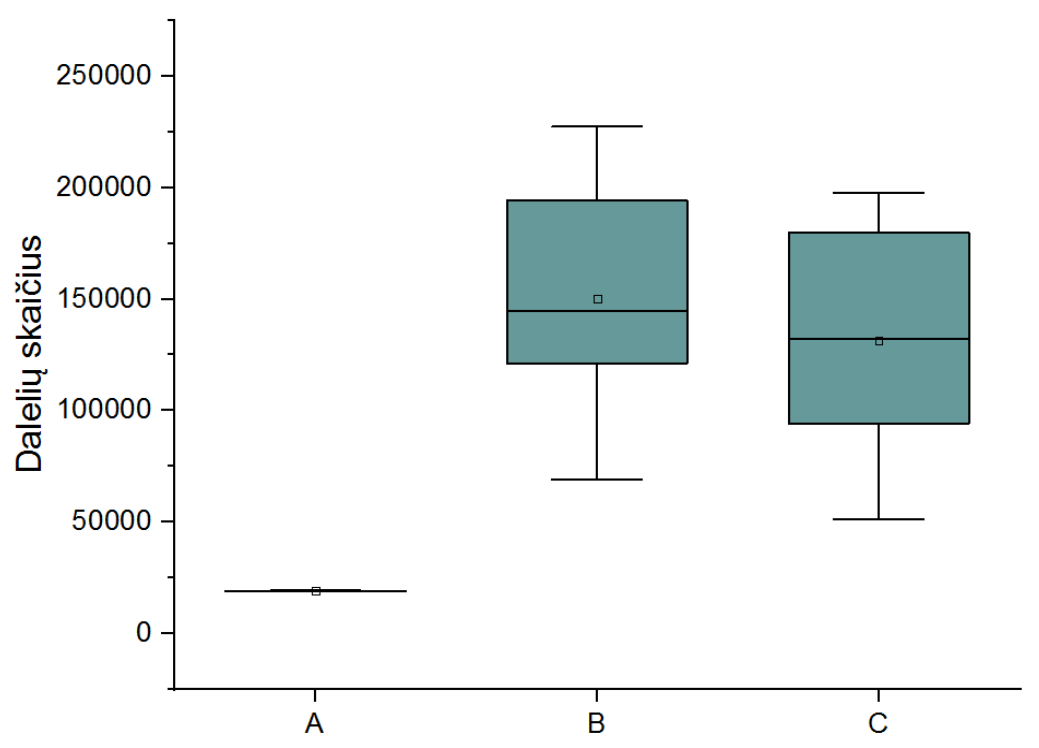

2 pav. Taršos kietosiomis dalelèmis reikšmė (intervale $0,2 \mu \mathrm{m}$ ), kur A - tarša prieš galandinimo procesą; B - tarša galandinimo proceso metu; $\mathrm{C}$ - tarša išvėdinus tiriamąą aplinką 1 valandą po galandinimo proceso

Fig. 2 Particulate pollution value (in the range of $0.2 \mu \mathrm{m}$ ), where $A$ is the pollution before the sharpening process; $B$ pollution during the sharpening process; $C$-pollution after derivation of the test environment 1 hour after the sharpening process

Pastebėta, kad jų kiekis yra labai artimas bendram kietųjų dalelių kiekiui, todèl galima teigti, kad jos naudojant ši matavimo prietaisą yra vyraujančios, nors kito prietaiso matavimo ribos buvo aukštesnès. Šis neatitikimas gali būti paaiškinamas skirtingu matavimo tikslumu (skiriasi matavimo prietaisų tikslumas). 


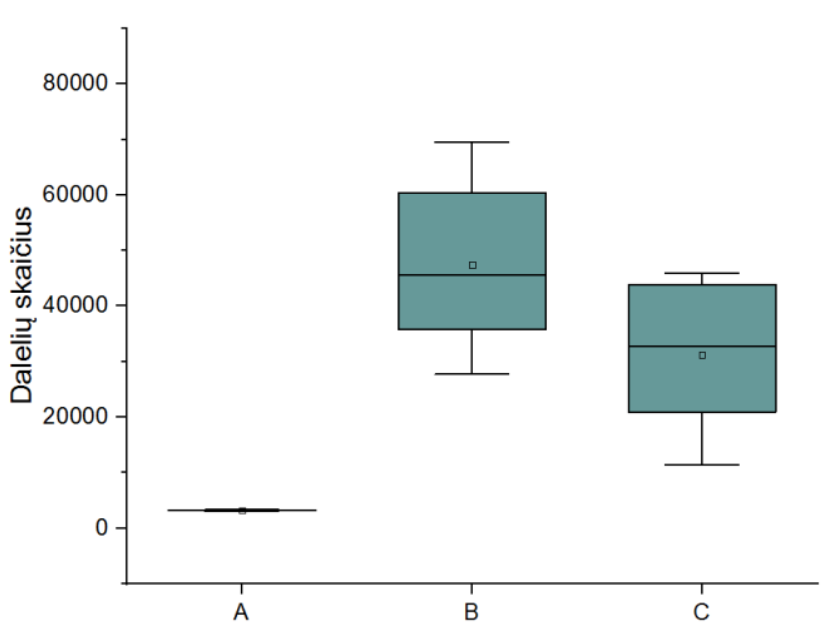

a)

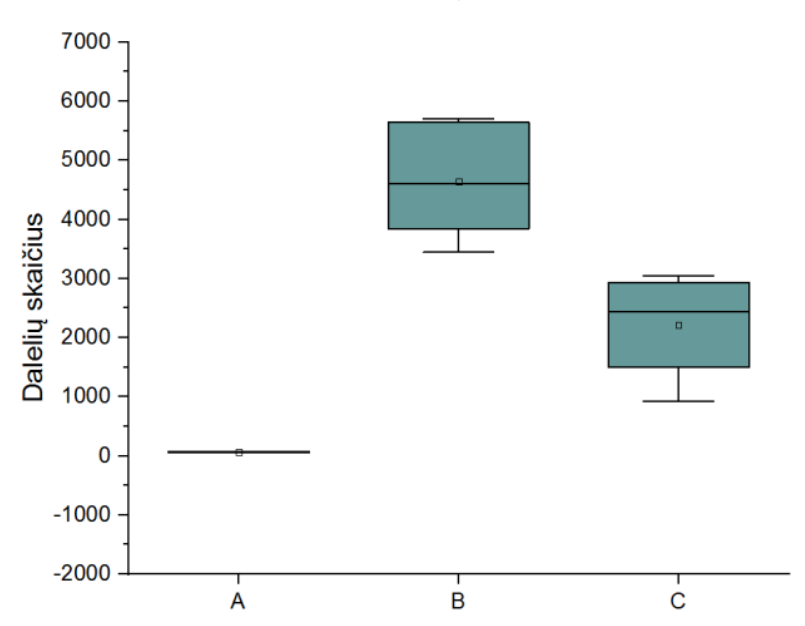

c)

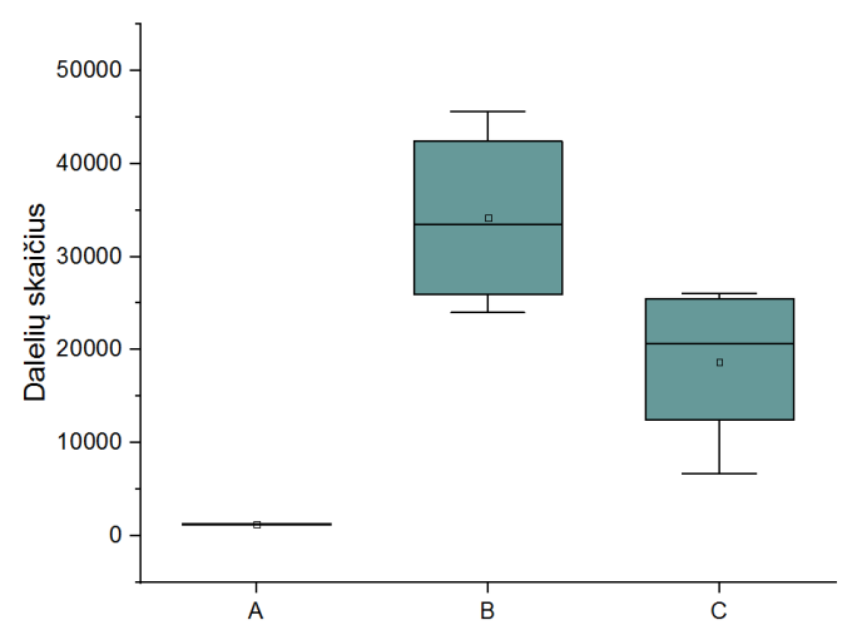

b)

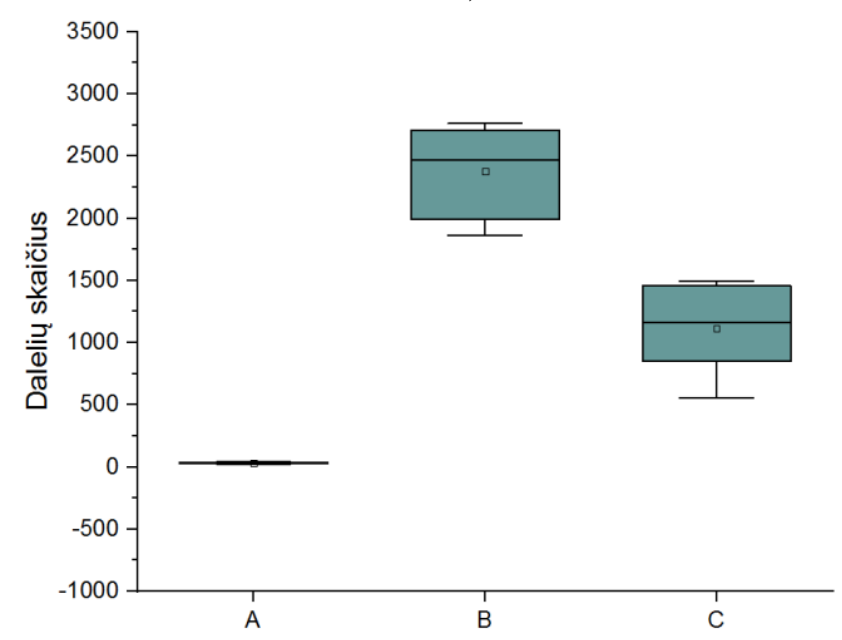

d)

3 pav. Taršos kietosiomis dalelėmis reikšmè, kur $\mathrm{A}$ - tarša prieš galandinimo procesą; $\mathrm{B}$ - tarša galandinimo proceso metu; $\mathrm{C}$ - tarša išvėdinus tiriamają aplinką 1 valandą po galandinimo proceso

Fig. 3 The value of particulate pollution, where A is the pollution before the sharpening process; $B$ - pollution during the sharpening process; $C$ - pollution after derivation of the test environment 1 hour after the sharpening process

Žiūrint i 3 (a-d) pav. pastebimas kietujjų dalelių skaičiaus mažèjimas didejjant jų dispersiškumui. Šios tendencijos yra logiškos vertinant tai, kad didesnès dispersijos kietosios dalelès turès didesnę masę ir nebus tokios aktyvios kaip mažesnès dispersijos kietosios dalelès.

Pastebima, kad didejjant kietųų dalelių dispersiškumui mažèjo jų išsibarstymo laukas, tai lèmè trumpesni kietųjų dalelių pakibimą matuojamoje terpèje ir atitinka kitų autorių darbuose nurodytas tendencijas dèl kietujų dalelių masès ir išsilaikymo ore formuojant pirminius ir antrinius aerozolius.

\section{Išvados}

1. Analizuojant pačių mažiausių dalelių $(0,2 \mu \mathrm{m})$ pasiskirstymą pastebèta (2 pav.), jų kiekis nors ir yra mažesnis patalpai išvėdinant vieną valandą, bet pakankamai didelis. Tai gali lemti darbo sąlygu pablogèjimą, kuris turi įtakos darbo efektyvumui. Pirmą kartą registruojamų transporto priemonių skaičiaus analizė parodè ekonominès krizès laikotarpius, kurie neišryškëjo nagrinèjant bendrą transporto priemonių skaičiaus pokyčio tendenciją. 
2. Galandinimo proceso metu pastebimas kietųų dalelių skaičiaus mažèjimas didèjant jų dispersiškumui. Šios tendencijos yra logiškos vertinant tai, kad didesnès dispersijos kietosios dalelès turès didesnę masę ir nebus tokios aktyvios kaip mažesnès dispersijos kietosios dalelès.

\section{Literatūra}

1 1-1 Dèl Galios elektros ịrenginių ịrengimo taisykliu patvirtinimo (2012). Prieiga internete: https://www.etar.lt/portal/legalAct.html?documentId=TAR.242AFDBB5BC9 (accessed 2.14.20).

2 1-211 Dèl Elektriniu ir elektros tinklų eksploatavimo taisyklių patvirtinimo. (2012). Prieiga internete: https://www.e-tar.lt/portal/lt/legalAct/TAR.22696B8593A1 (accessed 2.14.20).

3 Bandyopadhyay, A., Zhang, Y., Bose, S., (2020). Recent developments in metal additive manufacturing. Curr. Opin. Chem. Eng. 28, 96-104. https://doi.org/10.1016/j.coche.2020.03.001

4 Chen, R., Yin, H., Cole, I.S., Shen, S., Zhou, X., Wang, Y., Tang, S., (2020). Exposure, assessment and health hazards of particulate matter in metal additive manufacturing: A review. Chemosphere 259, 127452. https://doi.org/10.1016/j.chemosphere.2020.127452

5 Johnson, N.S., Vulimiri, P.S., To, A.C., Zhang, X., Brice, C.A., Kappes, B.B., Stebner, A.P., (2020). Invited review: Machine learning for materials developments in metals additive manufacturing. Addit. Manuf. 36, 101641. https://doi.org/10.1016/j.addma.2020.101641

6 Liu, C., (2021). Digital Twin-enabled Collaborative Data Management for Metal Additive Manufacturing Systems 18.

7 Maldonado-Macías, A., García-Alcaraz, J., Reyes, R.M., Hernández, J., (2015). Application of a Fuzzy Axiomatic Design Methodology for Ergonomic Compatibility Evaluation on the Selection of Plastic Molding Machines: A Case Study. Procedia Manuf. 8.

8 Merklein, M., Schulte, R., Papke, T., (2021). An innovative process combination of additive manufacturing and sheet bulk metal forming for manufacturing a functional hybrid part. J. Mater. Process. Technol. 291, 117032. https://doi.org/10.1016/j.jmatprotec.2020.117032

9 Molaei, R., Fatemi, A., Phan, N., (2021). Notched fatigue of additive manufactured metals under axial and multiaxial loadings, Part I: Effects of surface roughness and HIP and comparisons with their wrought alloys. Int. J. Fatigue 143, 106003. https://doi.org/10.1016/j.ijfatigue.2020.106003

10 Petunin, A.A., Polishchuk, E.G., Ukolov, S.S., (2019). On the new Algorithm for Solving Continuous Cutting Problem. IFAC-Pap. 52, 2320-2325. https://doi.org/10.1016/j.ifacol.2019.11.552

11 Rostek, T., Homberg, W., (2017). Locally Graded Steel Materials for Self-Sharpening Cutting Blades. Procedia Eng. 207, 2185-2190. https://doi.org/10.1016/j.proeng.2017.10.979

12 Senthil, S., Raguraman, M., Thamarai Manalan, D., (2020). Manufacturing processes \& recent applications of aluminium metal matrix composite materials: A review. Mater. Today Proc. S2214785320366827. https://doi.org/10.1016/j.matpr.2020.08.792

13 Singh, H., Saxena, P., Puri, Y.M., (2020). Materials selection and manufacturing of metal membranes for industrial applications. Mater. Lett. 269, 127557. https://doi.org/10.1016/j.matlet.2020.127557

14 V-520 Dèl Lietuvos Respublikos sveikatos apsaugos ministro 2000 m. gegužès 24 d. ịsakymo Nr. 277 "Dèl L... (2014). Prieiga internete: https://e-seimas.Irs.lt/portal/legalAct/lt/TAD/6377be60d58711e3b272e0e81c552d38 (accessed 1.6.21).

15 V-1081 Dèl Lietuvos higienos normos HN 42:2009 "Gyvenamujų ir visuomeniniu pastatu patalpu mikroklimatas... (2009). Prieiga internete: https://e-seimas.lrs.lt/portal/legalAct/lt/TAD/TAIS.362676 (accessed 1.6.21).

16 XIII-2711 Lietuvos Respublikos ịstatymas dèl Tarptautinès darbo organizacijos $1930 \mathrm{~m}$. konvencijos dèl prive... (2019). Prieiga internete: https://www.e-tar.lt/portal/lt/legalAct/370d23702ad511eabe008ea93139d588 (accessed 2.14.20).

\section{Investigation of Particulate Pollution During the Sharpening Process}

(Received in January, 2021; Accepted in February, 2021; Available Online from 11 ${ }^{\text {th }}$ of May, 2021)

\section{Summary}

With the modernization of industry and the increasing demands to ensure the sustainability of the working environment due to possible health disorders in the workplace environment, it was decided to examine the changes in pollution of particulate matter released during processing. Small solids are particularly permeable enough to pen-etrate 
not only the smallest points of the bronchial lung, but can also contaminate blood circulation and cause chronic heart disease, so the study chose one of the possible operations of the metalworking process (sharpening process) and decided to identify the change in particulate pollution, assess the shortcomings of the working envi-ronment and provide effective solutions.

The study was carried out in a work environment with a worker working on a metal sharpening machine using steel blanks and directly measuring the amount of solids formed in three stages: before starting work, during work and 1 hour after turning off the sharpening machine (afternoon breaktime). For this purpose, particulate analyzers were used to determine the amount of particulate matter in the current operating environment.

To evaluate the results of the particulate test, we divided them into two parts, the general particulate test by summarizing the total particulate concentration (particle size measured in the range of 2.5-10 microns) and the particulate test according to their dispersity for the ranges $0.2 \mu \mathrm{m}, 0.5, \mathrm{~m}, 1 \mu \mathrm{m}, 3 \mu \mathrm{m}, 5 \mu \mathrm{m}, 10 \mu \mathrm{m}$.

Analyzing the distribution of the smallest particles $(0.2 \mu \mathrm{m})$, it was observed that their amount, although smaller after ventilating the room for one hour, is large enough to cause complications for the human body. This can lead to a deterioration of the working conditions, which affects the efficiency of the work. It has also been found that during the sharpening process a decrease in the number of solid particles is observed with increasing dispersibility. These trends are logical in considering that higher dispersion solids will have a higher mass and will not be as active as lower dispersion solids. 